\title{
Michel Collot, Le chant du monde dans la poésie française contemporaine
}

\section{Fabio Scotto}

\section{(2) OpenEdition}

1 Journals

\section{Edizione digitale}

URL: https://journals.openedition.org/studifrancesi/21752

DOI: 10.4000/studifrancesi.21752

ISSN: 2421-5856

\section{Editore}

Rosenberg \& Sellier

\section{Edizione cartacea}

Data di pubblicazione: 1 décembre 2019

Paginazione: 610

ISSN: 0039-2944

\section{Notizia bibliografica digitale}

Fabio Scotto, «Michel Collot, Le chant du monde dans la poésie française contemporaine», Studi Francesi [Online], 189 (LXIII | III) | 2019, online dal 01 mars 2020, consultato il 12 novembre 2021. URL: http:// journals.openedition.org/studifrancesi/21752 ; DOI: https://doi.org/10.4000/studifrancesi.21752

Questo documento è stato generato automaticamente il 12 novembre 2021.

\section{(c) (i) (9)}

Studi Francesi è distribuita con Licenza Creative Commons Attribuzione - Non commerciale - Non opere derivate 4.0 Internazionale. 


\title{
Michel Collot, Le chant du monde dans la poésie française contemporaine
}

\author{
Fabio Scotto
}

\section{NOTIZIA}

Michel Collot, Le chant du monde dans la poésie française contemporaine, Paris, Éditions Corti, 2019, «Les Essais», 354 pp.

1 Si devono a Michel Collot, professore emerito di letteratura francese alla Sorbonne nouvelle-Paris 3, alcuni degli studi sulla poesia francese contemporanea e il suo rapporto col paesaggio fra i più significativi dell'ultimo trentennio. Di approccio fenomenologico, la sua ricerca ha introdotto nel paesaggio critico alcuni concetti come «la structure d'horizon» (La poésie moderne et la structure d'horizon, Paris, PUF, 1989) e La matière-émotion (ivi, 1997), rivelatisi assai utili per orientare la riflessione verso un rapporto tra soggetto esperente e mondo, necessaria a superare talune aporie del dibattito e della pratica contemporanea, spesso arroccata su formalismi estenuanti o su soggettivismi eccessivamente autotelici.

Questo nuovo, avvincente volume di studi rappresenta nel contempo l'estensione e il coronamento di un itinerario che opportunamente oscilla tra la riflessione teorica pura e la lettura analitica dei testi, con esiti tanto più pervasivi quanto più l'aspetto speculativo, sempre lucido e documentato, trova poi nell'approccio ai testi un motivo di espansione e di speculare rispecchiamento nelle pratiche poetiche correnti, delle quali (basti pensare ai suoi approfonditi studi su Reverdy, Ponge, du Bouchet, Supervielle) Collot è uno dei più rigorosi e accreditati specialisti.

3 L'opera ha una struttura tripartita. Nella Premessa introduttiva, «Un paysage brouillé» (pp. 7-12), l'A. delinea lucidamente le problematiche attuali della poesia francese, contesa fra avanguardismi "post-poetici" tendenti all'illeggibilità, con conseguente allontanamento dei lettori, e ritorni neo-liristici alla tradizione, pur rifuggendo da ogni artificiale dualismo antitetico fra questi orientamenti, se, come egli scrive, «le lyrisme 
moderne est inséparable d'un travail sur la matière des mots et du monde» e «isoler le travail sur la langue de l'expression d'un sujet tarit une des sources de l'émotion poétique, qui repose sur l'interaction du moi, du monde et des mots» (p. 11). L'uscita dall'antitesi bloccante, che si riflette anche nel sempre più difficile rapporto con $\mathrm{i}$ lettori e con i media e l'editoria specializzata, è a suo avviso quello di aprire la ricerca tanto letteralista quanto lirica al mondo, ai luoghi e al paesaggio, ovvero alla relazione (Édouard Glissant) e a una nuova oralità, tale da fare udire «le chant du monde» (ottimistico auspicio che, secondo noi, forse in più casi però collide con il palese rifiuto della volontà di "relazione" e con l'inammissibilità della nozione stessa di "canto" in poesia propugnata da molti formalisti odierni).

Nella sezione «Tendances» (pp. 15-98), il critico affronta alcune questioni nodali del dibattito odierno quali quella della storia della poesia del Secondo Novecento - che, al di là delle rispettive dichiarazioni d'intenti, mostra tuttavia taluni elementi di convergenza, come, ad esempio, la presenza di elementi autobiografici nell'ostentato oggettivismo di Jean-Marie Gleize (p. 33) -, il rapporto fra lirismo e letteralismo e l'ibridazione fra verso e prosa.

5 La successiva sezione «Le chant du monde» (pp. 101-171) si addentra nelle tematiche caratterizzanti del pensiero dell'A., ovvero un'oralità poetica che dia voce al mondo, il rapporto con la natura e i suoi luoghi in una prospettiva anche ecologica e geopoetica (si pensi a riguardo a Kenneth White), mentre la terza e conclusiva intitolata «Lectures» (pp. 205-344) sposta il focus su alcune pratiche contemporanee tra le più rilevanti in tale prospettiva, con saggi su Bernard Noël, Michel Deguy, Jean-Paul Michel, Lionel Ray, Jean-Claude Pinson, il compianto Antoine Emaz, da poco scomparso, Philippe Jaccottet, Pierre Chappuis, François Cheng, André Velter.

6 Ne risulta un caleidoscopio suggestivo e stimolante, che si muove al di fuori di schemi fissi e di valori scontati, per cercare all'interno di ogni percorso poetico e riflessivo una singolare «résonance de l'espace» (p. 341), ovvero un'interazione di vista e udito d'ascendenza indubbiamente baudelairiano-rimbaudiana, tale $\mathrm{da}$ ampliare "l'orizzonte" sensibile e mentale del poeta e di chi delle sue feconde intuizioni fruisce attraverso il "sublime" che può diventarne la lettura.

7 Di Michel Collot corre l'obbligo di segnalare altresì il precedente volume di saggi Sujet, monde et langage dans la poésie moderne. De Baudelaire à Ponge (Paris, Classiques Garnier, 2018, «Études de littérature des $\mathrm{xx}^{\mathrm{e}}$ et $\mathrm{xxI}^{\mathrm{e}}$ siècles» 74, 276 pp.), che, su analoghi presupposti critici e teorici, raccoglie pregevoli studi su autori otto-novecenteschi, da Baudelaire e Rimbaud a Claudel, da Apollinaire, Reverdy e Supevielle a Ponge, con esiti altrettanto illuminanti e convincenti. 